\title{
Overview on nanotechnology based cosmeceuticals to prevent skin aging
}

\author{
Gizem Otlatıcı', Gizem Yeğen', Sevgi Güngör², Buket Aksu* \\ 'Department of Pharmaceutical Technology, Faculty of Pharmacy, Istanbul Altınbaș University, Istanbul, Turkey \\ ${ }^{2}$ Department of Pharmaceutical Technology, Faculty of Pharmacy, Istanbul University, 34116, Istanbul, Turkey
}

Cite this article as: Otlatıcı G, Yeğen G, Güngör S, Aksu B. Overview on nanotechnology based cosmeceuticals to prevent skin aging. Istanbul J Pharm 48 (2): 55-62.

\begin{abstract}
Skin aging is an inevitable process and the highest contributing factor to this process is the effect of ultraviolet rays. However, nutrients, dry skin, smoking, hormones and gravity are also other important factors. Skin aging is classified as intrinsic (chronological) and extrinsic (photo-aging). Generally, in aged skin, effects such as thinning, loss of elasticity, spotting, wrinkles and sagging are observed.

There are various approaches to preventing skin aging. The most widely used age combating substances in cosmeceuticals are kinetin, retinoids, sun filters, herbal ingredients (such as resveratrol, turmeric, and green tea), and antioxidants (such as alpha-tocopherol, ascorbic acid, coenzyme Q10 and lipoic acid). In recent years, these molecules have been formulated as nanosized carriers such as vesicular systems, polymeric and lipid nanoparticles, nanoemulsions, dendrimers, and fullerenes. Novel carrier systems have a lot of advantages when compared to conventional formulations. In this review, an overview of cosmetic, product-oriented solutions for skin aging is given and different approaches to combat aging are summarized.
\end{abstract}

Keywords: Skin aging, cosmeceuticals, antioxidants, anti-aging, nanocarriers, vesicles

\section{INTRODUCTION}

The skin is the largest organ of the body and constitutes $16 \%$ of body weight. It provides the primary passage between the external environment and the body (Wickett and Visscher, 2006; Wato and Skazik, 2012). Human skin has many functions including protecting internal organs from physical and chemical trauma and ultraviolet rays, preventing microorganism entry and preventing dermal water and electrolyte loss (Bouwstra and Honeywell-Nguyen, 2002; Ramos-e-Silva and De-Moura-Castro, 2010). It also plays an active role in defence as a physical barrier - it is important to defend against the biochemical barrier consisting of lipids, acids, hydrolytic enzyme, antimicrobial peptides and the immunological barrier of humoral and cellular components of immune system (Proksch et al., 2008; Baroni et al., 2012). As well as ensuring an ideal site for the administration of therapeutic compounds for local and systemic effects, skin also offers a formidable barrier against the permeation of most compounds (Benson and Watkinson, 2012) with its three main layers. These are; the epidermis, dermis and hypodermis (Darlenski and Fluhr, 2012).

Aging is a consequence of both genetic programming in the body and the occurrence of cumulative environmental effects on the skin. The skin is the first organ where signs of aging are observed (Ünlü and Erdem, 2010). Aging processes happen at intrinsically different rates depending on genetic regulation, toxicity of some products on metabolism and repair (Yazan et al., 2016). The factors which have an important role in aging can be divided into four basic categories: biological (genetically determined and unchangeable), environmental (exposure to sunlight, pollution or nicotine), mechanical aging (recurrent muscle movements), and miscellaneous factors such as diet, morbidity, sleep patterns, and mental health (Farage et al., 2007). 
Skin aging is a complex, multi-factorial phenomenon involving both intrinsic (true, chronological) and extrinsic (photo-aging) processes (Farage et al., 2007). These parallel processes contribute to the loss of the structural integrity and physiological function of the skin, which inevitably leads to death. Environmental factors such as ultraviolet (UV) exposure to the sun, smoking, environmental pollution and the natural aging process contribute to the formation of free oxygen radicals and affect the inflammatory process of skin (Türsen, 2006).

Intrinsic aging (time-dependent natural aging) is a period that starts with the slowing of cell renewal and continues with chronological and genetic causes. Over time, the amount of keratinocyte and fibroblast that accumulates in the skin increases and the rate of aging increases, the tissue becomes hardened and wrinkles appear (Farage et al., 2007). Furthermore, intrinsic aging leads to a decrease in subdermal fat tissue. This loss of support causes sagging (laxity) of the skin. Due to a loss of padding, skin is more susceptible to bruising and trauma (McCullough et al., 2006). Extrinsic aging (photo-aging) can occur with environmental stress factors (such as climate conditions, air pollution, sun rays) or unconscious use of products that come in contact with the skin. Exposure to UV rays damages collagenous tissue and the elastin network, causing free radical formation. Thus, cell renewal diminishes and hyperpigmentation, dryness and wrinkles occur (Farage et al., 2007). The photo-aged skin appears wrinkled, saggy and hard, and pigmentation differentiations are observed (Zussman et al., 2010).

UV-initiated photo-damage-cascade reaction cascade inhibition strategies are as follows;

- Blockung UV penetration of the skin with physical \& chemical sunscreens

- Reduction and prevention of inflammation with anti-inflammatory compounds

- Cleaning and removal of reactive oxygen radicals with antioxidants

- Inhibition of ECM damage and MMP (Matrix MetalloProteinase) activation by prevention of neutrophil elastase activity

- Prevention of MMP expression by retinoids and inhibition of its activity by synthetic or natural inhibitors (Türsen, 2006).

In cosmetic products, various active ingredients and different agents can be used to prevent, delay and to treat skin aging. These agents can be grouped as antioxidants, biological growth factors and kinetin, herbal ingredients, retinoids, acids of natural origins and its derivatives, and sun filters (Yazan, 2004).

Conventional carriers for cosmetic products can demonstrate low efficiency as cosmeceuticals since they have little affinity for skin and have very little percutaneous absorption. New technology has shown tremendous potential to improve the effectiveness and efficiency of delivery of cosmeceuticals and bioactive compounds. The recent developments in nanotechnology indicate their potential as carriers of cosmetics for plant extracts, phytochemicals and other active ingredients which are poorly soluble, poorly absorbed and unstable. The application of new approaches can also enhance the effectiveness of active substances regarding their continuous action on the human body. Today, there is a considerable number of products available on the market with improved efficacy (Chasteen et al., 2011). The novel carriers used can be grouped as vesicular systems - including liposomes, niosomes, transfersomes, ethosomes, nanoemulsions, solid lipid nanoparticles, nanocapsules - and other nanosized delivery systems (Chanchal and Swarnlata, 2008).

\section{Active cosmetic ingredients used against skin aging}

Although the best strategy for photo-aging is still prevention, different agents are used in the delay and treatment of skin aging. Anti-aging formulations have two basic groups of substances that are used in their compositions. These are antioxidant substances and cell-regulating substances. Antioxidants such as vitamins, polyphenols and flavonoids decrease collagen degradation by decreasing free radical concentration in tissues. Cell regulators such as retinols and growth factors are directly involved in collagen metabolism and increase collagen production (Yapar and Tanriverdi, 2016).

Antioxidants: Free radicals are thought to cause lipid peroxidation, DNA damage and inflammation leading to aging. Antioxidants can prevent these events by reducing free radicals (Türsen, 2006). Vitamin antioxidants are vitamin $\mathrm{E}$ (alpha-tocopherol), vitamin C (ascorbic acid), beta carotene, nicotinamide, vitamin $\mathrm{K}$ and coenzyme Q10. Enzymatic antioxidants are glutathione peroxidase, superoxide dismutase and lipoic acid.

Biological growth factors and kinetin: The plant growth hormone Kinetin (N6-furfuryladenine), is a cytokine. It is a strong antioxidant, so will therefore protect against the oxidative damage caused by the sun's rays and decrease the signs of sun related aging (Tirnaksız, 2005). Depending on time and environmental factors, aging of the skin causes the collagen and elastin network structure in the dermis to deteriorate. When the photo aging changes in the skin are examined pathophysiologically, it appears that there is a correlation between acute and chronic damage healing. Growth factors in this process stimulate glycosaminoglycan (GAG) and collagen and elastin synthesis, which are the major components of the dermal extracellular matrix (Werner and Grose, 2003). The most frequently used growth factors in cosmetic products are epidermal growth factor (EGF), transforming growth factor, platelet derived growth factor, fibroblast growth factor, insulin like growth factor and interleukin (Yazan et al. 2016).

Herbal extracts: Herbal extracts are used for dermatological purposes either as oral supplements or as a component of topical formulations. Various herbals in skin care products are called cosmeceuticals. Over centuries or millennia, plants have adapted to an environment with continual detrimental oxidative attack and, in this way, a lot of botanicals display powerful antioxidant activities. Additionally, most herbals rely on several protective responses and often exhibit multiple responses at the same time e.g. pigment-lightening, antioxidant, anti-carcinogenic and anti-inflammatory activity (Allemann and Baumann, 2009). 
Retinoids: Retinoids are described as vitamin A derivatives. Naturally occurring retinoids are required for the differentiation and epithelial tissue function. Retinol is a popular cosmetic ingredient used since it effects the appearance of photo-damage and cellulite (Shapiro and Saliou, 2001). Tretinoin is the most studied topical retinoid regarding photoaging. Isotretinoin, retinaldehyde and tazarotene are less studied than tretinoin, however their results are also promising. Benefits of retinoids are fixing fine-wrinkles, decreasing roughness and hyperpigmentation (Sorg et al., 2005).

Acids of natural origins and their derivatives: Hyaluronic acid (HA), known as hyaluronan, is a major and important component of skin and it has a role in tissue repair. Also, it has a significant role in providing skin firmness and structure. Photo-damaged skin produces less hyaluronic acid, and it leads to hyaluronic acid deficiency, consequently wrinkles occur. Local application of hyaluronic acid has helped in providing healthy collagen levels and moisturising skin (Sharma and Sharma, 2012).

Alpha hydroxy acids (AHA) are natural organic acids found in some foods. The most well-known is glycolic acid. In photoaging treatment, AHAs are effective agents - with proper formulation and $\mathrm{pH}$. It was found that products combined with AHA were more effective than retinoic acid alone. However, it was emphasized that combined products produced more irritation (Lazarus and Baumann, 2001).

Salicylic acid is the most frequently used Beta-hydroxy acid (BHA). Recently, salicylic acid has been used in photo-aging treatment in 20-30\% of peelings. These can be very helpful for patients who cannot tolerate alpha hydroxy acids because irritancy levels of salicylic acid are lower compared with AHAs. In addition, because the operational mechanisms are different, it can be very beneficial to combine or alternate both AHA and $\mathrm{BHA}$, and using both of them can be very useful (Graf, 2005).

Sun filters: Sunscreen must be able to reduce the MED (Minimal Erythemal Dose) value caused by UV radiation by 25 times and delay the formation of underwater erythema for 8 hours when exposed to sunlight for 20 minutes. New sun protection products have also been developed to prevent sunlight from reaching the skin and repair sun-damaged skin. Sun protection products that provide protection by covering the skin are the most effective in protecting from sunburn and erythema caused by high-energy UV rays. However, the photo aging effect of these sunscreen agents is related to low-energy UV radiation blocking capacities (Yazan et al. 2016). Sunscreen must be safe for the environment as well, as when it becomes waste it is possible to enter the body in different ways. A significant amount of UV absorber remains on the surface of water and in waste water (Gondikas et al., 2014).

\section{Novel topical delivery strategies of active cosmetic in- gredients to prevent skin aging}

Topical delivery of the active ingredients for effective treatment depends on two main criteria. Firstly, they have to reach the site of action in substantial levels, and secondly, they have to remain at the site of action in an effective concentration for a certain time (Gupta et al., 2012, Güngör et al., 2013). It is intended that the majority of conventional topical preparations are delivered locally to the targeted site instead of a systemic action of the drug.

Skin is an easily accessible organ for drug administration. However, this does not necessarily mean that the active ingredients have easy access to the site of action (Barry, 1987; Gupta et al., 2012). Conventional topical formulations that normally require the use of ointments or creams have some limitations, such as the patient's compliance, and safety and effectiveness of the treatment. Drugs from such preparations are split when applied to the skin and produce a highly concentrated layer of active ingredient that is rapidly absorbed (Nacht and Katz, 1990). The high concentration of active ingredients is necessary for the effective administration of these agents due to of the inefficiency of the conventional delivery system. It may result in toxic reactions such as irritation or allergic reactions. Other hazards include uncontrolled evaporation of the active substance and unpleasant odour (Pradhan, 2011). Pharmacokinetic data also indicates that low absorption of the drug from the conventional formulation might be observed. Furthermore, sometimes the application of topical drugs results in lack of patient compliance because of the problems of greasiness and stickiness often associated with ointments.

As a first approach in topical treatment, penetration enhancers such as dimethyl sulfoxide or propylene glycol derivatives have been used to increase drug penetration through targeted skin layers. The addition of penetration enhancers in formulations increases the transport rate through the epidermal barrier, but additionally increases unwanted effects due to the increased drug level in the blood. The reports demonstrate that irritation or even toxic side effects of penetration enhancers can be observed and this questions their use in topical drug administration (Barry, 1987; Gupta et al., 2012).

In addition, novel drug delivery systems are being investigated that offer the potential to reduce such erroneous characteristics without diminishing the efficacy of the active ingredients. New topical carriers seem to have achieved previously unattainable targets and have overcome the issues associated with conventional topical treatment. The application of such novel nanosized vehicle systems means that they are capable of delivering potent drugs to the preferred region in a precise manner. The design of nanomedicine is based on nano-systems. These effectively control the release of a therapeutic moiety with a localized effect for the affected skin area by creating skin reservoirs. Nanosized particles and their narrow size distribution may also allow an effective site-specific skin targeting to have a higher drug retention rate (Gupta et al., 2012, Güngör, 2014).

Cosmetic nanoparticles can be produced in different compositions, shapes, structures and with different properties. The intended uses of nanoparticles in cosmetic products are summarized below (Tarımcı and Badıllı, 2014):

- Enhancing the encapsulation and stability of sensitive materials such as unsaturated fatty acids, vitamins or antioxidants in nanostructures,

- Increasing penetration of cosmeceuticals through the epidermis, 
- Ensuring that the active substances are transported to the targeted skin layers,

- Lowering costs by preparing more effective formulations of expensive materials,

- $\quad$ Providing a controlled release of cosmetic active ingredients,

- Minimizing irritation to the skin due to encapsulation of the active substances with irritant properties in the carrier system,

- Increasing the efficiency and tolerance of UV filters such as $\mathrm{TiO}_{2}$ and $\mathrm{ZnO}$ on the skin surface.

The nanoparticles used in cosmetic formulations can be separated into two main groups, organic and inorganic nanoparticles. The most commonly used inorganic nanoparticles are $\mathrm{TiO}_{2}$ and $\mathrm{ZnO}$, which are water and oil insoluble metal oxide nanoparticles. $\mathrm{TiO}_{2}$ and $\mathrm{ZnO}$, which are widely used in cosmetic preparations such as lotions and sunscreen, are effective and photo-stable physical UV filters that absorb UVB and UVA radiation. In order to increase the filtration capacities and the transparency properties, it is desirable to have sizes between 60 and $200 \mathrm{~nm}$. The surfaces of these inorganic nanoparticles are usually coated with neutral materials such as aluminium oxide, poly-siloxane compounds, or silicone oils, in order to improve their dispersibility, photo-stability and activity in the product.

The second group of nanoparticles, which are widely used in cosmetic products, are nanocarrier systems (Tarımcı and Badıllı, 2014; Morganti, 2010) which provide more effective delivery of active cosmetic ingredients to the skin. The first systems used for this purpose are liposomes and niosomes. The newer systems, solid lipid nanoparticles and nanostructured lipid carriers, are both more stable than liposomes in terms of their stability and effectiveness.

\section{Vesicular systems}

Liposomes: Liposomes are spherical vesicles containing a phospholipid and cholesterol bilayers (Rahimpour and Hamishehkar, 2012). This type of structure makes it possible to incorporate the lipophilic drug into the lipid bilayer as well as the hydrophilic drug in the aqueous compartment (Jaspart et al., 2005). To target the active ingredients, the lipid bilayer may combine with the cell membrane, thus delivering the liposome contents (Kaur et al., 2007). Due to having similar lipids to the epidermis, liposomes can reduce systemic absorption while improving dermal drug delivery (Yang et al., 2009).

Niosomes: Niosomes are closed double layered structures formed by non-ionic surfactants in an aqueous media. Niosomes first appeared at the beginning of the 1970s following research by L'Oreal and were first used for cosmetic purposes. Topical application of niosomes provides benefits such as increasing the duration of the substances in the stratum corneum and epidermis and increasing skin penetration (Tarımcı and Badıllı, 2014).

Transfersomes: Deformable liposomes (transfersomes) are elastic and defined as ultra-elastic liposomes which can be deformed to a high degree. They are a critical advance in topical vesicular drug delivery, and they have the potential to dramati- cally improve drug delivery (Gupta et al., 2012). It has been reported that the stratum corneum can be rapidly penetrated by the intercellular route since their structures can be deformed to a high degree (Tao, 2000).

Ethosomes: In the process of exploring new approaches to improved cutaneous delivery, ethosomes have proven to be potential carriers regarding dermatology. Recently developed ethosomes have shown enhanced skin delivery of the encapsulated drug. The only difference between conventional liposomes and ethosomes is that ethosomes are composed of ethanol rather than cholesterol (Gupta et al., 2012). Ethosomes are lipid-carrier systems which can be single or multilayered structures consisting mainly of phospholipids, ethanol and water. The ethosome name emphasizes the presence of ethanol in high concentrations (20-45\%). It is reported that ethosomes can efficiently trap molecules with various lipophilic properties and can enhance the permeation of these substances (Touitou et al., 2000; Sinico and Fadda, 2009).

\section{Nanoemulsions}

Nanoemulsions are thermodynamically stable, transparent nano-dispersions that are smaller than $100 \mathrm{~nm}$ in droplet size, stabilized by an interfacial film formed by surfactant and cosurfactant molecules. Nanoemulsions, being one of the most promising delivery systems for the topical application of active ingredients, are hugely important for the future of cosmetic products, as well as for their use in pharmaceutical and biomedical applications (Tarımcı and Badıllı, 2014). Nanoemulsions create a large surface to volume ratio for the emulsion particles in contact with the skin. Consequently, due to enhanced surface interaction between the skin and the emulsion, more active substances come into contact with the skin's surface. Small emulsion particles will not block the pores and let air and water flow between them. The nanodroplets have a liquid and lipophilic core surrounded by a monomolecular layer of phospholipids meaning that they are different from liposomes which have an aqueous core surrounded by a phospholipid double layer. Due to the lipophilic insides, they are more appropriate for lipophilic compounds delivery when compared to liposomes. Nanoemulsions have their own bioactive effect and strengthen the skin barrier function by reducing transepidermal water loss (Kaur and Agrawal, 2007).

\section{Lipid nanoparticles}

Lipid nanoparticles have a similar structure to nanoemulsions. They are submicron colloidal carriers, usually between 40 and $1000 \mathrm{~nm}$ in size. The difference is that the lipid core is solid. The matrix comprises a single solid lipid or lipid mixtures. The term "lipid" includes triglycerides, partial glycerides, fatty acids, steroids and waxes (Guimarães and Ré, 2011).

Solid lipid nanoparticles (SLN) have been developed as an alternative to conventional colloidal carrier systems such as liposomes and polymeric nanoparticles (Müller, 1991). The greatest advantages of SLNs are these: they are biologically degradable, they are prepared with lipids which are physiological compounds, they can provide controlled release of the substances, and they can remain stable for long periods in the form of aqueous dispersions (Müller et al., 2002). 
Nanostructured lipid carriers (NLC) are second generation lipid nanoparticles and prepared with solid and liquid lipid mixture. They offer advantages such as higher loading efficiency and reduced risk of leakage of lipid matrix material during storage (Müller et al., 2007). Newly developed lipid nanoparticlederived NLCs give better results in overcoming the problems associated with SLNs - often with limited drug loading, the risk of gelation and drug leakage in storage caused by lipid polymorphism (Gupta et al., 2012).

\section{Nanocapsules}

Nanocapsules are spherical, colloidal systems smaller than $1000 \mathrm{~nm}$ consisting of a core, acting as a liquid reservoir for molecules, and a polymeric shell acting as a protective membrane. Polymeric nanocapsules were first introduced to the cosmetic market in 1995 by L'Oreal (Guterres et al., 2007; Shakeel et al., 2012).

\section{Other types of nanocarriers}

As well as the aforementioned nanocarriers, dendrimers and fullerenes are also drawing attention in the cosmetic field (Tarımcı and Badıllı, 2014). When a dendrimer is compared to classical polymers, it has a highly branched, tree-like three-dimensional structure. Dendrimers consist of a series of chemical shells built around a small core molecule consisting of four major components: a central or core unit, identical sized arms, interconnections or branch points, and end functional groups (Kaur and Agrawal, 2007).

Fullerene is an archetypal bucky balls example. It is defined as a compound composed only of an even number of carbon atoms, which form a lattice-like merged-ring polycyclic system, with 12 five-membered rings and the rest being sixmembered rings. Fullerene and its derivatives are particularly water-soluble (Kaur et al., 2007). Oval or tube-shaped fullerene molecules, which are formed entirely from carbon, are also becoming of greater interest in cosmetics due to their biological antioxidant potential and their protective effects against UVA radiation (Bakry et al., 2007).

A lot of research has been carried out in the use of nanocarrier systems in cosmetics and there are many examples of cosmetic products containing nanocarrier systems on the market. The following table contains examples of different commercially available nanocarrier systems (Kaur and Agrawal, 2007; Sharma and Sharma, 2012; Li et al., 2011).

Examples of recent research studies relating to the delivery of active compounds encapsulated in nanocarriers are given in Table 1. According to these studies, the following results are noteworthy. Coenzyme Q 10 in proniosome form provides better photo-protection compared to free Coenzyme Q10. The NLC form enhances better skin penetration and antioxidant effects than emulsions but the ultra-small NLC form of Coenzyme Q10 increases the dermal presentation when compared to classic NLC (Yadav et al., 2016; Schwarz et al., 2013; Yue et al., 2010). The phyto-vesicular form of curcumin is the most effective form among liposomes and niosomes. However, out of the liposome, ethosome and transfersome forms of curcuma longa extract, transfersome is the most effective form (Kaur and Saraf, 2011; Gupta and Dixit, 2011). Resveratrol and curcumin have low water solubility and therefore their skin penetration is difficult. However, thanks to lipid core nanocapsules, their penetration through the skin can be achieved (Friedrich et al., 2015). In recent years, nano-sized micellar carriers have also been considered as potential systems for the targeted delivery of compounds into skin layers such as hair follicles and has proven effective in the treatment of acne (Kahraman et al. 2016, Kandekar et al. 2018).

Examples of commercial products used as anti-aging products where nanocarriers are used are given in Table 2.

\section{CONCLUSION}

Skin aging is a complex biological process that is caused by internal and external factors or their association and some 80-90 $\%$ is caused by UV light. Harmful conditions such as malnutrition, intense stress, hormonal factors, environmental pollution, smoking and alcohol use are other factors that affect skin aging. The changes that are most likely to occur on the skin with aging are dryness, thin and deep wrinkles and loss of normal elasticity.

There are different approaches to preventing skin aging that can be classified simply as novel and conventional approaches. Solutions, gels, emulsions, suspensions, powder preparations and aerosols are accepted as classical carrier systems for topical delivery. However, these conventional topical options have limitations and are compromised in terms of safety and effectiveness of the treatment. In order to overcome these problems, novel drug carrier systems have been developed. The active ingredients, namely antioxidants, growth factors and herbal components, may be administered in a carrier system. Novel carrier systems have properties such as providing sustained action, enhancing the stability of the active ingredients, reducing the irritation levels of the materials, and increasing skin penetration. In vitro and in vivo studies are important for efficacy and safety of the product. For this reason, it is necessary to carry out increasingly more precise tests on cosmetics before they are introduced to the market.

Coenzyme Q10, rice bran extract, alpha-lipoic acid, curcuma longa extract, resveratrol, kinetin, rosemary extract, alpha-tocopherol are the most studied substances for novel carrier systems such as solid lipid nanoparticles, niosomes, and nanostructured lipid carriers. Considering the fact that the herbal components are sometimes beneficial in terms of biodegradation and low toxicity, the use of plant components in cosmetic formulations has been studied with liposomes, phytosomes, transferosomes, nanoemulsions, nanoparticles, microemulsions, nanocrystals and cubosomes. Importantly, nanoemulsions are the most effective cosmetics and are preferred as distributors of active ingredients to specific skin layers. Vesicular systems (liposomes, niosomes, etc.) are also favoured when formulating the active ingredients of anti-aging cosmetic. By using vesicular systems, transepidermal water loss can be prevented, and the stability of vitamins along with the restorative effect is ensured. Sunscreen active ingredients can be encapsulated in microcapsules. Also, lipid-core nanocapsules have been shown to have great poten- 
Table 1. Research studies after 2010 on delivery of active compounds via nanocarriers

\begin{tabular}{|c|c|c|c|}
\hline $\begin{array}{l}\text { Active } \\
\text { Substance }\end{array}$ & $\begin{array}{l}\text { Type of } \\
\text { nanocarriers used }\end{array}$ & Study outcome & Reference \\
\hline \multirow[t]{3}{*}{ Coenzyme Q 10} & Proniosome & $\begin{array}{l}\text { Histopathological studies have shown that CoQ10 PN } \\
\text { gel-treated skin provides better protection compared to free } \\
\text { CoQ10. It has been observed that the PN gel form also has } \\
\text { more effective antioxidant properties in photo protection. }\end{array}$ & Yadav et al., 2016 \\
\hline & Ultra small NLC & $\begin{array}{l}\text { Ultra small NLC (80nm) CoQ10 has been shown to improve } \\
\text { dermal presentation when compared to larger, classical NLC. } \\
\text { This study clearly showed that curcumin phyto-vesicle was } \\
\text { more effective than other forms in terms of anti-aging, } \\
\text { antioxidant, and anti-wrinkle effect.to improve dermal } \\
\text { presentation when compared to larger, classical NLC. }\end{array}$ & Schwarz et al., 2013 \\
\hline & NLC & $\begin{array}{l}\text { Study revealed that CoQ10-NLC has advanced antioxidant } \\
\text { effects and stronger penetration than general CoQ10 emulsions. }\end{array}$ & Yue et al., 2010 \\
\hline Curcumin & $\begin{array}{l}\text { Phytovesicles } \\
\text { Liposome } \\
\text { Niosome }\end{array}$ & $\begin{array}{l}\text { This study clearly showed that curcumin phyto-vesicle was } \\
\text { more effective than other forms in terms of anti-aging, } \\
\text { antioxidant, and anti-wrinkle effect. }\end{array}$ & $\begin{array}{l}\text { Gupta and } \\
\text { Dixit, } 2011\end{array}$ \\
\hline Resveratrol & Liposome \& noisome & $\begin{array}{l}\text { This study have shown that niosomes made from lipophilic } \\
\text { surfactant were able to deliver resveratrol to the skin to } \\
\text { achieve a topical effect. Additionally, niosome improve both } \\
\text { dermal and transdermal resveratrol delivery in comparison } \\
\text { with conventional liposomes. }\end{array}$ & Pando et al., 2013 \\
\hline $\begin{array}{l}\text { Resveratrol \& } \\
\text { Curcumin }\end{array}$ & $\begin{array}{l}\text { Lipidcore } \\
\text { nanocapsules }\end{array}$ & $\begin{array}{l}\text { Co-encapsulation led to a faster release of resveratrol, while } \\
\text { the curcumin release rate remained constant. Skin penetration } \\
\text { studies showed an increased delivery to deeper skin layers of } \\
\text { resveratrol when given in combination with encapsulation } \\
\text { of a single polyphenol. Lipid core nanocapsules have a great } \\
\text { potential as carrier systems for application of low water-soluble } \\
\text { compounds such as resveratrol and curcumin to human skin. }\end{array}$ & Friedrich et al.,2015 \\
\hline Rice bran extract & Niosome & $\begin{array}{l}\text { This study showed the stimulation on the growth of human } \\
\text { fibroblast and inhibition of MMP- } 2 \text { activity of the semi-purified } \\
\text { rice bran extracts and, the improvement of skin properties } \\
\text { including hydration, pigmentation, thickness and roughness, and } \\
\text { skin elasticity. Also, chemical stability of the bioactive compounds } \\
\text { in the extracts was enhanced by entrapping iniosomes. }\end{array}$ & Manosroi et al., 2012 \\
\hline $\begin{array}{l}\text { 5-aminolevulinic } \\
\text { acid }\end{array}$ & Liposomal spray & $\begin{array}{l}\text { The study showed that IPL-PDT therapy using } 0.5 \% \text {-ALA } \\
\text { spray and the Ellipse Flex PPT system resulted in a significant } \\
\text { improvement in both periorbital and nasolabial wrinkles } \\
\text { in type } 2 \text { photo-damaged patients. }\end{array}$ & Piccioni et al., 2011 \\
\hline $\begin{array}{l}\text { Alpha-lipoic } \\
\text { acid }\end{array}$ & Cubosome & $\begin{array}{l}\text { Decrease in facial lines, almost complete healing of fine lines } \\
\text { in the periorbital area and upper lid, and a general improvement } \\
\text { in skin color and texture in most volunteers was observed. }\end{array}$ & Sherif et al., 2014 \\
\hline Kinetin (N6FA) & SLN & $\begin{array}{l}\text { The skin treated with N6FA loaded SLNs clearly demonstrated } \\
\text { its efficacy in the prevention of photoaging }\end{array}$ & Goindi et al., 2015 \\
\hline $\begin{array}{l}\text { Curcuma } \\
\text { longa extracts }\end{array}$ & $\begin{array}{l}\text { Etosome } \\
\text { Transfersome } \\
\text { Liposome }\end{array}$ & $\begin{array}{l}\text { The photoprotective properties of nano-vesicles with C. longa } \\
\text { extract, photoprotective features of moisturizing lipid } \\
\text { components, improved skin properties such as skin hydration } \\
\text { and sebum content with better skin penetration. It has been } \\
\text { concluded that extract-loaded transfersomes are more } \\
\text { effective for improving skin properties than ethosomes } \\
\text { and liposomes. }\end{array}$ & Kaur and Saraf, 2011 \\
\hline
\end{tabular}

tial as carrier systems for local application of low water solubility compounds such as resveratrol and curcumin to the skin. Reasons for choosing these approaches in cosmetic formulations are as follows: there is a need for a formulation in which the structure of a substance, mixture or plant extract, exhibits desirable properties in vitro conditions, is supported by in vivo studies and can be delivered to the targeted site without chemical modification or altering its structure.
New generation cosmeceuticals based on developing production technologies and the use of novel delivery carrier systems in cosmetic formulations offer advanced cosmetic care alternatives. The development of cosmetic products using advanced active cosmetic ingredients, the increased use of natural source raw materials as cosmetic ingredients, and the use of new, nanosized carrier systems in cosmetic formulations aim to meet the increasing societal demands and expectations of cosmetics. 
Table 2. Commercial products used as anti-aging products in the market

\begin{tabular}{|c|c|c|c|c|}
\hline Trade Name & Active Ingredient & Proposed Use & Name of Company & $\begin{array}{l}\text { Nanotechnology } \\
\text { Used }\end{array}$ \\
\hline Platinéum & Hydroxyapatite & Anti-aging & Lancôme & Nanoparticles \\
\hline Gold Future & Gold & Anti-free radicals & Helena Rubinstein & Colloidal \\
\hline Revitalift & Pro-retinol A & Anti-aging & L'Oreal & Nanosome \\
\hline Revitalift double lifting & Pro-retinol A, Pro-tensium & Intense re-tightening & L'Oreal & Nanosome \\
\hline Rénergie Microlift & $\begin{array}{l}\text { Micro filters } \\
\text { (silica and protein) }\end{array}$ & $\begin{array}{l}\text { Anti-aging } \\
\text { Moisturizer }\end{array}$ & L'Oreal & Nanoparticles \\
\hline Smooth $\mathrm{E}$ & Titanium dioxide, zinc oxide & Sunscreen & Doctor Cosmetic Lab & Nanocomplex \\
\hline Rovisome ACE Plus & $\begin{array}{l}\text { Ascorbyl palmitate, } \\
\text { Tocopherol retinol }\end{array}$ & $\begin{array}{l}\text { Anti- aging } \\
\text { Anti-wrinkle }\end{array}$ & $\begin{array}{l}\text { Rovi Cosmetics } \\
\text { International } \mathrm{GmbH}\end{array}$ & Liposome \\
\hline Ageless Facelift cream & $\begin{array}{l}\text { CoenzymeQ10, } \\
\text { Niacinamide }\end{array}$ & $\begin{array}{l}\text { Anti-aging } \\
\text { Antioxidative } \\
\text { Anti-wrinkle }\end{array}$ & I-Wen Naturals & Liposome \\
\hline Nano-lipobelle H-AECL & Vitamin A, E and C & $\begin{array}{l}\text { Anti-aging } \\
\text { Anti-wrinkle }\end{array}$ & $\begin{array}{l}\text { Mibelle Biochemistry, } \\
\text { Switzerland }\end{array}$ & Nanoemulsion \\
\hline $\begin{array}{l}\text { Lancôme Soleil } \\
\text { Soft-Touch Anti-Wrinkle } \\
\text { Sun Cream SPF } 15\end{array}$ & Vitamin E, Panthenol & $\begin{array}{l}\text { Anti-aging } \\
\text { Revitalizing }\end{array}$ & L'Oreal & Nanocapsule \\
\hline $\begin{array}{l}\text { Sircuit Addict Firming } \\
\text { Antioxidant Serum }\end{array}$ & $\begin{array}{l}\text { Grape seed extract, } \\
\text { Vitamin E, Green tea }\end{array}$ & $\begin{array}{l}\text { Anti-aging } \\
\text { Revitalizing }\end{array}$ & $\begin{array}{l}\text { Sircuit Skin } \\
\text { Cosmeuticals Inc. }\end{array}$ & Fullerene \\
\hline
\end{tabular}

Conflict of Interest: The authors have no conflict of interest to declare.

\section{REFERENCES}

- Allemann IB, Baumann, L. (2009). Botanicals in skin care products. 48(9): 923-934.

- Bakry R, Vallant RM, Najam-ul-Haq M, Rainer M, Szabo Z, Huck CW, Bonn GK. (2007). Medicinal applications of fullerenes. 2(4): 639.

- Baroni A, Buommino E, De Gregorio V, Ruocco E, Ruocco V, Wolf R. (2012). Structure and function of the epidermis related to barrier properties. 30(3), 257-262. [CrossRef]

- $\quad$ Barry BW. Penetration enhancers. In: Shroot B, Schafer H, 1987 editors. Skin Pharmacokinetics. Karger, Basel. pp. 121-7

- Benson HA, Watkinson AC. (Eds.). (2012). Topical and transdermal drug delivery: Principles and practice. John Wiley \& Sons.

- Bouwstra JA, Honeywell-Nguyen PL. (2002). Skin structure and mode of action of vesicles. 54: S41-S55.

- Chanchal D, Swarnlata S. (2008). Novel approaches in herbal cosmetics. J Cosmet Dermatol 7(2): 89-95. [CrossRef]

- Chasteen AL, Bashir NY, Gallucci C, Visekruna A. (2011). Age and antiaging technique influence reactions to age concealment. 66(6): 719-724.

- Darlenski R, Fluhr JW. (2012). Influence of skin type, race, sex, and anatomic location on epidermal barrier function. 30(3): 269-273.

- Ezzat SM, Salama MM, EIMeshad AN, Teaima MH, Rashad LA. (2016). HPLC-DAD-MS/MS profiling of standardized rosemary extract and enhancement of its anti-wrinkle activity by encapsulation in elastic nanovesicles. 39(7): 912-925.

- $\quad$ Farage MA, Miller KW, Elsner P, Maibach HI. (2007). Structural characteristics of the aging skin: a review. 26(4): 343-357.

- Friedrich RB, Kann B, Coradini K, Offerhaus HL, Beck RC, Windbergs M. (2015). Skin penetration behavior of lipid-core nanocapsules for simultaneous delivery of resveratrol and curcumin. 78 : 204-213 [CrossRef]

- Goindi S, Guleria A, Aggarwal N. (2015). Development and Evaluation of Solid Lipid Nanoparticles of N-6-Furfuryl Adenine for Prevention of Photoaging. 11(10): 1734-1746.
Gökce EH, Korkmaz E, Dellera E, Sandri G, Bonferoni MC, Ozer O. (2012). Resveratrol-loaded solid lipid nanoparticles versus nanostructured lipid carriers: evaluation of antioxidant potential for dermal applications. 7(1), 1841-1850. [CrossRef]

- Gondikas AP, Kammer FVD, Reed RB, Wagner S, Ranville JF, Hofmann T. (2014). Release of TiO2 nanoparticles from sunscreens into surface waters: a one-year survey at the old Danube recreational Lake. $\mathbf{4 8}(10)$ : 5415-5422.

Graf J. (2005). Anti-aging skin care ingredient technologies. In: Cosmetic Dermatology Springer, Berlin Heidelberg. pp. 17-28. [CrossRef]

- Guimarães KL, Ré MI. (2011). Lipid nanoparticles as carriers for cosmetic ingredients: The first (SLN) and the second generation (NLC). In: Nanocosmetics and nanomedicines, Springer, Berlin Heidelberg. pp. 101-122. [CrossRef]

- Gupta M, Agrawal U, Vyas SP. (2012). Nanocarrier-based topical drug delivery for the treatment of skin diseases. 9(7): 783-804.

- Gupta NK, Dixit VK. (2011). Development and evaluation of vesicular system for curcumin delivery. 303(2): 89-101.

- Guterres SS, Alves MP, Pohlmann AR. (2007). Polymeric nanoparticles, nanospheres and nanocapsules, for cutaneous applications. 2: $147-157$

- Güngör S, Erdal MS, Aksu B. (2013). New formulation strategies in topical antifungal therapy. 3(01): 56-65.

- Güngör S. (2014). Topikal Uygulanan Nanotaşıyıcılar, In: ZırhGürsoy A (ed.) Nanofarmasötikler ve Uygulamaları. Aktif Matbaa ve Reklam Hiz. San. Tic. A.Ş. İstanbul, pp. 333-345.

- Jaspart S, Piel G, Delattre L, Evrard B. (2005). Solid lipid microparticles: formulation, preparation, characterisation, drug release and applications. 2(1): 75-87.

- Kahraman E, Özhan G, Özsoy Y, Güngör S. (2016). Polymeric micellar nanocarriers of benzoyl peroxide as potential follicular targeting approach for acne treatment. 146: 692-699.

- Kandekar SG, Del Río-Sancho S, Lapteva M, Kalia YN. (2018). Selective delivery of adapalene to the human hair follicle under finite dose conditions using polymeric micelle nanocarriers. 10(3): 1099-1110. 
- $\quad$ Kaur CD, Saraf S. (2011). Topical vesicular formulations of Curcuma longa extract on recuperating the ultraviolet radiation-damaged skin. 10(4): 260-265.

- $\quad$ Kaur IP, Agrawal R. (2007). Nanotechnology: a new paradigm in cosmeceuticals. 1(2): 171-182 [CrossRef]

- $\quad$ Kaur IP, Kapila M, Agrawal R. (2007). Role of novel delivery systems in developing topical antioxidants as therapeutics to combat photoageing. 6(4): 271-288.

- $\quad$ Kwon SS, Kim SY, Kong BJ, Kim KJ, Noh GY, Im NR, Park SN. (2015). Cell penetrating peptide conjugated liposomes as transdermal delivery system of Polygonumaviculare L. extract. 483(1): 26-37.

- Lazarus, M. C., \& Baumann, L. S. (2001). The use of cosmeceutical moisturizers. 14(3): 200-207.

- $\quad$ Li D, Wu Z, Martini N, Wen J. (2011). Advanced carrier systems in cosmetics and cosmeceuticals: a review. $\mathbf{6 2}(6): 549$

- Manosroi A, Chutoprapat R, Abe M, Manosroi W, Manosroi J. (2012). Anti-aging efficacy of topical formulations containing niosomes entrapped with rice bran bioactive compounds. $\mathbf{5 0}$ (2): 208-224.

- McCullough JL, Kelly KM. (2006). Prevention and treatment of skin aging. 1067(1): 323-331.

- Morganti, P. (2010). Use and potential of nanotechnology in cosmetic dermatology. Clin Cosmet Investig Dermatol 3: 5-13. [CrossRef]

- Müller RH. (1991). Colloidal carriers for controlled drug delivery and targeting: Modification, characterization and in vivo distribution. Taylor \& Francis.

- Müller RH, Petersen RD, Hommoss A, Pardeike J. (2007). Nanostructured lipid carriers (NLC) in cosmetic dermal products. 59(6): 522-530 [CrossRef]

- Müller RH, Radtke M, Wissing SA. (2002). Solid lipid nanoparticles (SLN) and nanostructured lipid carriers (NLC) in cosmetic and dermatological preparations. 54: S131-S155.

- $\quad$ Nacht S, Katz M. The microsponge: A novel topical programmable delivery system. (1990).In: Osborne DW, Amman AH, editors. Topical Drug Delivery Formulations. Marcel Dekker Basel, New York. p. 299-325

- $\quad$ Pando D, Caddeo C, Manconi M, Fadda AM, Pazos C. (2013). Nanodesign of olein vesicles for the topical delivery of the antioxidant resveratrol. 65(8): 1158-1167.

- $\quad$ Piccioni A, Fargnoli MC, Schoinas S, Suppa M, Frascione P, Ginebri A, Peris K. (2011). Efficacy and tolerability of 5-aminolevulinic acid $0.5 \%$ liposomal spray and intense pulsed light in wrinkle reduction of photodamaged skin. 22(5): 247-253.

- $\quad$ Pradhan SK. (2011). Microsponges as the versatile tool for drug delivery system. 1(2), 243-58.

- $\quad$ Proksch E, Brandner JM, Jensen JM. (2008). The skin: an indispensable barrier. 17(12): 1063-1072.

- Rahimpour Y, Hamishehkar H. (2012). Liposomes in cosmeceutics. 9(4): 443-455.

- $\quad$ Ramos-e-Silva M, Jacques CDMC. (2012). Epidermal barrier function and systemic diseases. 30(3): 277-279.
Schwarz JC, Baisaeng N, Hoppel M, Löw M, Keck CM, Valenta C. (2013). Ultra-small NLC for improved dermal delivery of coenyzme Q10. $\mathbf{4 4 7}(1): 213-217$.

Shakeel F, Shafiq S, Haq N, Alanazi FK, Alsarra IA. (2012). Nanoemulsions as potential vehicles for transdermal and dermal delivery of hydrophobic compounds: an overview. 9(8): 953-974.

Sharma B, Sharma A. (2012). Future prospect of nanotechnology in development of anti-ageing formulations. 4: 57-66.

Sherif S, Bendas ER, Badawy S. (2014). The clinical efficacy of cosmeceutical application of liquid crystalline nanostructured dispersions of alpha lipoic acid as anti-wrinkle. 86(2): 251-259.

Sinico C, Fadda AM. (2009). Vesicular carriers for dermal drug delivery. $\mathbf{6}(8)$ : 813-825

Sorg O, Kuenzli S, Kaya G, Saurat JH. (2005). Proposed mechanisms of action for retinoid derivatives in the treatment of skin aging. 4(4): 237-244.

Tao L. (2000). Skin delivery from lipid vesicles. 115(4): 43-50.

- Tarımcı N, Badıllı U S. (2014). Nanotaşıyıcıların Kozmetik Uygulamaları, In: Zırh-Gürsoy A (ed.) Nanofarmasötikler ve Uygulamaları. Aktif Matbaa ve Reklam Hiz. San. Tic. A.Ş. İstanbul, pp. 347-359.

Tırnaksız F. (2005). Antioksidanların cilt bakım ürünlerinde kullanımı. Teb Meslek içi Eğitim Dergisi. Kasım, pp. 26-37.

- Touitou E, Dayan N, Bergelson L, Godin B, Eliaz M. (2000). Ethosomes-novel vesicular carriers for enhanced delivery: characterization and skin penetration properties. 65(3): 403-418.

- Türsen Ü. (2006). Deri Yaşlanmasının Topikal Ajanlarla Önlenmesi. 4: $267-283$.

Ünlü E. (2010). Erdem C. Deri yaşlanmasında korunma ve tedavi yöntemleri. 1(1), 23-31.

- Wickett RR, Visscher MO. (2006). Structure and function of the epidermal barrier. 34(10): S98-S110.

- Yadav NK, Nanda S, Sharma G, Katare OP. (2016). Systematically optimized coenzyme q10-loaded novel proniosomal formulation for treatment of photo-induced aging in mice: characterization, biocompatibility studies, biochemical estimations and anti-aging evaluation. 24(3): 257-271.

Yang D, Pornpattananangkul D, Nakatsuji T, Chan M, Carson D, Huang CM, Zhang L. (2009). The antimicrobial activity of liposomal lauric acids against Propionibacterium acnes. 30(30): 60356040.

- Yapar EA, Tanrıverdi ST. (2016). Yaşlanma Karşıtı Kozmetik Yaklaşımlar ve Ürün Bileşenleri. ıkesir Sağlık Bilimleri Dergisi 5(2): 99-109.

Yazan Y. (2004). Kozmetik Bilimi. Nobel Tıp Kitabevleri/Istanbul.

- Yazan Y. (2016). Dermakozmetik/Kozmesötik Madde ve Ürünler. Nobel Tıp Kitabevleri/Istanbul.

- Yue Y, Zhou H, Liu G, Li Y, Yan Z, Duan M. (2010). The advantages of a novel CoQ10 delivery system in skin photo-protection. $\mathbf{3 9 2}(1)$ : 57-63.

Zussman J, Ahdout J, Kim J. (2010). Vitamins and photoaging: Do scientific data support their use? $\mathbf{6 3}(3)$ : 507-525. 